\title{
Evaluation of Characters for Ascertaining Salt Stress Responses in Lycopersicon Species
}

\author{
v. Cruz and J. Cuartero \\ Estacion Experimental La Mayora, Consejo Superior de Investigaciones Científicas, \\ 29750-Algarrobo, Málaga, Spain
}

\author{
M.C. Bolarin and M. Romero \\ Centro de Edafologia y Biologia Aplicada del Segura, Consejo Superior de Investigaciones \\ Cientificas, Apartado 195, 30080-Murcia, Spain
}

Additional index words. tomato, Lycopersicon esculentum, L. peruvianum, L. pimpinellifolium, L. hirsutum, L. pennellii, $\mathrm{NaCl}$ tolerance

\begin{abstract}
Plant height; stem thickness; fresh and dry weights of leaves and stems; numbers of leaves, trusses, flowers, and fruits; and leaf concentrations of $\mathrm{Cl}, \mathrm{Na}, \mathrm{N}-\mathrm{NO}_{3}, \mathrm{~K}, \mathrm{Ca}$, and $\mathrm{Mg}$ were measured in mature plants from 39 tomato accessions representing five species of Lycopersicon [L. esculentum Mill., L. peruvianum (L.) Mill., L. pimpinellifoliurn (Jusl.) Mill., L. hirsutum H. \& B., L. pennellii (Corr.) D'Arcy] in response to various NaCl concentrations. Plants were irrigated with a nutrient solution, plus one of four levels of $\mathrm{NaCl}$ with electrical conductivities of 0.28 , 0.63 , 1.39, and $2.15 \mathrm{~S} \cdot \mathrm{m}^{-1}$. Characters were evaluated for each genotype taking into consideration: 1) the significant differences between $\mathrm{NaCl}$ concentrations, 2) the experimental errors in the analyses of variance, and 3) the uniformity of response to the salt concentrations. The characters that fulfilled these criteria for all 39 genotypes were: plant height, dry weights of leaves, fresh and dry weights of stems, and leaf concentrations of $\mathrm{Cl}$ and Na. However, other characters, although not generally applicable to the entire data set, were good indicators of response differences within a particular species. Leaf concentrations of $\mathrm{N}-\mathrm{NO}_{3}$ and $\mathrm{Mg}$ were useful indicators in $L$. pimpinellifolium and L. esculentum and number of leaves and leaf concentration of $\mathrm{Mg}$ were useful indicators in $L$. hirsutum for responses of mature plants to salt stress.
\end{abstract}

Breeders developing crops tolerant to saline soils find it difficult to choose traits. to use as markers for the reliable assessment of salt tolerance (Epstein, 1983). Ideally, characters should be simple to measure and permit the identification of salinity tolerance during seed germination or at the seedling stage. Methodology should be precise, economical, and relatively rapid. Salt tolerance of young tomato (Lycopersicon esculentum) plants is not well correlated with that of mature plants (Guerrier, 1984; Norlyn and Epstein, 1984; Shannon, 1979); consequently, our work was carried out with mature plants. Salt tolerance of mature plants has been measured by various indicators, such as mortality rate, root and shoot growth, plant height, number of leaves, leaf succulence and area, contents of amino acids and sugars, leaf electrical conductivity, fruit yield and quality, and the concentrations of $\mathrm{Na}, \mathrm{K}, \mathrm{Mg}, \mathrm{Cl}, \mathrm{Ca}$, and $\mathrm{N}-\mathrm{NO}_{3}$. Results for the different characters between genotypes and/or experiments are difficult to compare. For example, there were no significant differences in plant height among tomatoes that received different salt treatments, but there were differences between plant heights of saline-treated and control tomatoes (West et al., 1979). Sacher et al. (1982) and Shannon (1984) found that smaller losses of shoot dry and fresh weights than in the controls indicate greater salinity tolerance. However, these criteria are insufficient to rank various species according to their salt tolerance (Storey and Wyn Jones, 1977). Dehan and Tal (1978), Tal (1971), and Tal and Shannon (1983) concluded that the higher the salinity tolerance of tomato plants, the higher were the $\mathrm{Na}$ and $\mathrm{Cl}$ contents, but some tolerant hybrid lines of $L$.

Received for publication 11 July 1988. We gratefully acknowledge T.J. Flowers for his helpful suggestions when reviewing this work, D.W. Schofield for his translation of the manuscript, and CAICYT for the financial support by the project PA 85/140. The cost of publishing this paper was defrayed in part by the payment of page charges. Under postal regulations, this paper therefore must be hereby marked advertisement solely to indicate this fact. esculentum $x$ L. pennellii had concentrations of $\mathrm{Cl}$ and $\mathrm{Na}$ similar to those of salt-sensitive lines (Sacher et al., 1983).

Previous information on the response to saline stress of characters described in the literature is confusing, possibly because studies were carried out under diverse environmental conditions and with various genotypes. The objective of the present work was to choose characters that showed the smallest uncontrolled environmental variation with the strongest change with different salinity levels. Furthermore, the changes of characters should be repeatable among genotypes. Consequently, the 16 most commonly used characters in the literature were recorded for 39 genotypes of five species cultivated with four $\mathrm{NaCl}$ concentrations.

\section{Materials and Methods}

Thirty-nine genotypes of tomato consisting of 12 L. esculentum, 13 L. peruvianum, five L. pimpinellifolium, seven L. hirsutum, and two L. pennellii were used. Seeds were planted in rock wool (Grodan, Roermond, Holland) cubes (35 x 35 x $35 \mathrm{~mm}$ ). When the plants had two true leaves, each of the cubes was placed in a larger cube $(70 \times 70 \times 65 \mathrm{~mm})$. When the plants developed five true leaves, they were placed on rock wool packs $(100 \times 15 \times 7.5 \mathrm{~cm})$. Three plants were placed on each pack. The composition of the aqueous fertilizer solution was: (in $\mathrm{mol} \cdot \mathrm{m}^{-3}$ ) $\mathrm{K}_{2} \mathrm{~S} \mathrm{O}_{4}, 1.72 ; \mathrm{KNO}_{3}, 5.44 ; \mathrm{Ca}\left(\mathrm{NO}_{3}\right)_{2}, 3.05$; $\mathrm{N} \mathrm{H}_{4} \mathrm{~N} \mathrm{O}_{3}, 0.50 ; \mathrm{HNO}_{3}, 1.35 ; \mathrm{H}_{3} \mathrm{P} \mathrm{O}_{4}, 1.81$; (in $\mathrm{mmol} \cdot \mathrm{m}^{-3}$ ) $\mathrm{H}_{3} \mathrm{BO}_{3}, 16.70 ; \mathrm{ZnSO}_{4}, 1.38 ; \mathrm{CuSO}_{4}, 1.10 ;\left(\mathrm{NH}_{4}\right)_{6} \mathrm{Mo}_{7} \mathrm{O}_{24}, 0.52$; FeNa EDTA, 75.10; and $\mathrm{MnCl}_{2}, 16.40$.

For each genotype, 84 plants were cultivated in a plasticcovered greenhouse from April to September with minima and maxima of $22 \pm 1 \mathrm{C}$ and $37 \pm 2 \mathrm{C}$, respectively. The solar radiation in the greenhouse ranged between 225 to 760 $\mu \mathrm{mol} \cdot \mathrm{s}^{-1} \cdot \mathrm{m}^{-2}$, with an average of 605 . Plants were divided into four groups, one for each $\mathrm{NaCl}$ treatment. Each group was divided into three replications of seven plants. The seedlings 
Table 1. Percentage of the genotypes for which the saline treatments were statistically significant, percentage variance of experimental error in comparison with the total variance, and percentage of genotypes that displayed the same ranking of treatments for each character.

\begin{tabular}{|c|c|c|c|c|c|c|c|c|c|c|c|c|c|c|c|c|c|c|}
\hline \multirow[b]{3}{*}{ Character ${ }^{2}$} & \multicolumn{6}{|c|}{ Significant $\mathrm{NaCl}$ treatments $(\%)$} & \multicolumn{6}{|c|}{ Variance of experimental error $(\%)$} & \multicolumn{6}{|c|}{ Ranking of treatments (\%) } \\
\hline & \multicolumn{18}{|c|}{ Species ${ }^{y, x}$} \\
\hline & pim & per & pen & hir & esc & Global & pim & per & pen & hir & esc & Global & pim & per & pen & hir & esc & Globa \\
\hline Plant ht & 100 & 100 & 100 & 100 & 100 & 100 & 24 & 23 & 19 & 12 & 18 & 20 & 100 & 92 & 100 & 86 & 100 & 95 \\
\hline Leaves (no.) & 80 & 85 & 50 & 100 & 83 & 85 & 42 & 31 & 55 & 16 & 34 & 32 & 10 & 69 & 50 & 86 & 67 & 74 \\
\hline Trusses (no.) & 80 & 77 & 100 & 86 & 75 & 77 & 44 & 38 & 20 & 26 & 34 & 35 & 100 & 69 & 50 & 57 & 58 & 64 \\
\hline Flowers (no.) & 100 & 69 & 50 & 100 & 83 & 77 & 33 & 33 & 40 & 36 & 35 & 34 & 100 & 62 & 50 & 29 & 67 & 62 \\
\hline Fruits (no.) & 100 & 46 & 0 & 71 & 75 & 55 & 38 & 38 & 50 & 31 & 32 & 39 & 100 & 69 & 50 & 43 & 67 & 27 \\
\hline Leaf dry & 80 & 100 & 50 & 71 & 100 & 92 & 22 & 20 & 47 & 26 & 19 & 22 & 80 & 100 & 100 & 100 & 100 & 97 \\
\hline Stem fresh wt & 100 & 100 & 100 & 100 & 100 & 100 & 16 & 14 & 29 & 14 & 11 & 14 & 100 & 100 & 100 & 100 & 92 & 97 \\
\hline Stem dry wt & 80 & 100 & 100 & 100 & 100 & 97 & 23 & 14 & 26 & 16 & 12 & 16 & 100 & 100 & 100 & 100 & 100 & 100 \\
\hline $\mathrm{Cl}$ & 100 & 100 & 100 & 100 & 100 & 100 & 3 & 10 & 8 & 8 & 6 & 8 & 100 & 100 & 100 & 100 & 92 & 97 \\
\hline $\mathrm{Na}$ & 100 & 100 & 100 & 100 & 100 & 100 & 3 & 14 & 9 & 9 & 7 & 9 & 100 & 100 & 100 & 100 & 100 & 100 \\
\hline $\mathrm{K}$ & 80 & 92 & 100 & 86 & 100 & 92 & 33 & 40 & 15 & 23 & 25 & 30 & 80 & 46 & 50 & 86 & 83 & 69 \\
\hline
\end{tabular}

${ }^{2}$ Mineral contents refer to leaves.

"pim $=$ Lycopersicon pimpinellifolium, per $=$ L. peruvianum, pen $=$ L. pennellii, hir $=$ L. hirsutum, esc $=$ L. esculentum.

${ }^{x}$ Global refers to the whole group of genotypes without considering species separately.

initially were irrigated with the fertilizer solution, and after their establishment on the packs, each group was fertilized simultaneously with one of the saline treatments (i.e., $\mathrm{NaCl}$ at 0,2,4, or $8 \mathrm{~g} \cdot$ liter $^{-1}$ ) until the end of harvest. Plants were irrigated eight times daily with 0.1 liter/plant from the start of the experiment until day 19, 11 times daily with 0.1 liter/plant from day 19 to day 41, and 11 times daily with 0.14 liter/plant from day 41 to the end of the experiment (13 weeks). The small initial increments in salinity were chosen because an accumulationof salt in the rock wool substrate can be expected until equilibrium between the fertilizer solution and evapotranspiration is-reached. For this reason, the four $\mathrm{NaCl}$ concentrations measured $60 \mathrm{~min}$ after irrigation gave substrate electrical conductivities of $0.28,0.63,1.39$, and $2.15 \mathrm{~S} \cdot \mathrm{m}^{-1}$. The $\mathrm{pH}$ values were $6.86,6.84,6.40$, and 6.35 , respectively.

Sampling started 10 weeks after the beginning of saline treatments and consisted of randomly selecting three plants of each of the 39 genotypes from each replication in every treatment group. The following characteristics were measured: height of the main stem plant height), number of leaves, number of trusses, total number of flowers formed in each truss (number of flowers), stem thickness (beneath the fifth leaf), fresh weight of leaves (FWL), fresh weight of stem (FWS), dry weight of leaves (DWL), and dry weight of stem (DWS).

The leaves and stem of each plant were weighed separately, washed in distilled water, and dried at 65C. After 3 days, the tissues were weighed again to determine DWL and DWS. The dried leaf material of each plant was ground to pass through a $0.5-\mathrm{mm}$ mesh screen and used to determine the leaf concentrations of $\mathrm{Cl}, \mathrm{N}-\mathrm{NO}_{3}, \mathrm{Na}, \mathrm{K}, \mathrm{Ca}$, and $\mathrm{Mg}$. The leaf concentration of $\mathrm{Cl}$ was determined in the aqueous extract by potentiometric measurements with $\mathrm{AgNO}_{3}$ following the method of Johnson et al. (1958). Nitrogen-nitrate was determined in the aqueous extract by spectrophotometry at 210 and $270 \mathrm{~nm}$. For the determinations of cations, dried leaf material was digested in a 2 $\mathrm{HNO}_{3}$ : $1 \mathrm{HClO}_{4}$ mixture (v/v); $\mathrm{Na}$ and $\mathrm{K}$ were measured by emission spectrophotometry, and $\mathrm{Ca}$ and $\mathrm{Mg}$ by atomic absorption spectrophotometry.
Fruits from the four remaining plants in each replication were harvested three times to determine the average number of fruits per plant. Because L. peruvianum and L. hirsutum lines are not self-fertilizing, manual pollinations were made to obtain fruits from these accessions.

Analyses of variance of the factorial experiments were carried out for each one of the 16 characters in each genotype (624 analyses); the four saline concentrations and the three replications were the fixed main factors. The model for the analyses of variance was: $X_{i j}=m+T_{i}+R_{j}+T_{i j}+E$, where $m$ $=$ mean, $\mathrm{T}=$ saline treatment $(\mathrm{i}=1$ to 4$), \mathrm{R}=$ replication ( $\mathrm{j}=1$ to 3 ), and $E=$ error.

To evaluate the appropriateness of each character for salinity tolerance measurement, we took into account the following: 1) There were significant differences between salt concentrations in the analyses of variance of the 39 genotypes. 2) There was a minimum experimental error in the analyses of variance. To compare the error variances of the 624 analyses, their percentages of the total variance were calculated and those characters that exhibited the smallest percentages were considered more appropriate to evaluate salinity tolerance. 3) The rankings of the mean values of the characters in the Newman-Keuls tests were in a logical sequence with increase in the saline concentrations of the four treatments. Thus, the mean values for each character in the four treatments could be expected to either decrease or increase with increase of salt concentration. However, we decided that lack of significance between two consecutive values would not contravene this criterion.

\section{Results}

Significant differences were revealed among the salt treatments for plant height, FWS, and leaf $\mathrm{Cl}$ and $\mathrm{Na}$ concentrations for each of the 39 genotypes (Table 1). Because the genotypes were a sample from five species of Lycopersicon, the four characteristics (plant height, FWS, and leaf $\mathrm{Cl}$ and $\mathrm{Na}$ concentrations) revealed changes with the concentrations of $\mathrm{NaCl}$ independently of the genotypes used. Consequently, these char- 
Table 2. Effect of salinity on plant height, leaf dry weight (DWL), and fresh (FWS) and dry weights (DWS) of stem relative to control plants and on leaf $\mathrm{Cl}$ and $\mathrm{Na}$ concentrations for 39 genotypes.

\begin{tabular}{|c|c|c|c|c|c|c|c|}
\hline \multirow[b]{2}{*}{ Entry } & \multirow[b]{2}{*}{ Species $^{z}$} & \multirow[b]{2}{*}{$\begin{array}{c}\text { Plant } \\
\text { ht } \\
(\%)\end{array}$} & \multirow[b]{2}{*}{$\begin{array}{c}\text { DWL } \\
(\%)\end{array}$} & \multirow[b]{2}{*}{$\begin{array}{c}\text { FWS } \\
(\%)\end{array}$} & \multirow[b]{2}{*}{$\begin{array}{c}\text { DWS } \\
(\%)\end{array}$} & \multicolumn{2}{|c|}{ Leaf } \\
\hline & & & & & & $\begin{array}{l}\mathrm{Cl} \\
(\mu \mathrm{m} \\
\mathrm{dr}\end{array}$ & $\begin{array}{r}\mathrm{Na} \\
\cdot \mathrm{kg}^{-1} \\
\mathrm{wt}) \\
\end{array}$ \\
\hline 1 & pim & 79 & 104 & 67 & 74 & 2160 & 2010 \\
\hline 2 & pim & 72 & 48 & 45 & 39 & 1700 & 1610 \\
\hline 3 & pim & 80 & 50 & 50 & 50 & 1160 & 850 \\
\hline 4 & - pim & 70 & 41 & 47 & 49 & 1630 & 1500 \\
\hline 5 & pim & 78 & 48 & 44 & 47 & 1230 & 1160 \\
\hline 6 & per & 71 & 60 & 53 & 50 & 1020 & 290 \\
\hline 7 & per & 69 & 38 & 61 & 54 & 1600 & 920 \\
\hline 8 & per & 66 & 19 & 61 & 48 & 1570 & 1030 \\
\hline 9 & per & 72 & 43 & 56 & 50 & 1280 & 270 \\
\hline 10 & per & 70 & 44 & $4^{2}$ & 44 & 1210 & 620 \\
\hline-11 & per & 70 & 44 & 39 & 38 & 1190 & 270 \\
\hline 12 & per & 63 & 43 & 35 & 38 & 1450 & 450 \\
\hline 13 & per & 71 & 46 & 49 & 47 & 1250 & 620 \\
\hline 14 & per & 64 & 52 & 66 & 60 & 1030 & 220 \\
\hline 15 & per & 72 & 32 & 74 & 51 & 1700 & 440 \\
\hline 16 & per & 64 & 31 & 38 & 36 & 1520 & 490 \\
\hline 17 & per & 62 & 48 & 39 & 37 & 1710 & 1490 \\
\hline 18 & per & 69 & 44 & 42 & 40 & 1830 & 1570 \\
\hline 19 & pen & 76 & 72 & 41 & 41 & 1540 & 1610 \\
\hline 20 & pen & 80 & 46 & 48 & 46 & 1380 & 1310 \\
\hline 21 & hir & 65 & 81 & 40 & 43 & 1490 & 1350 \\
\hline 22 & hir & 62 & 40 & 38 & 44 & 1120 & 1120 \\
\hline 23 & hir & 58 & 53 & 46 ? & 41 & 1140 & 680 \\
\hline 24 & hir & 60 & 56 & 48 & 41 & 1260 & 1180 \\
\hline 25 & hir & 65 & 28 & 32 & 29 & 1250 & 1040 \\
\hline 26 & hir & 61 & 91 & 78 & 69 & 1120 & 980 \\
\hline 27 & hir & 61 & 48 & 76 & 66 & 1260 & 1180 \\
\hline 28 & esc & 85 & 66 & 73 & 68 & 3160 & 3160 \\
\hline 29 & esc & 81 & 80 & 68 & 70 & 2840 & 2730 \\
\hline 30 & esc & 74 & 65 & 63 & 64 & 2070 & 1670 \\
\hline 31 & esc & 74 & 81 & 66 & 63 & 2400 & 2340 \\
\hline 32 & esc & 65 & 75 & 54 & 54 & 2480 & 2670 \\
\hline 33 & esc & 65 & 58 & 43 & 36 & 2460 & 2680 \\
\hline 34 & esc & 67 & 62 & 67 & 56 & 2100 & 1510 \\
\hline 35 & esc & 70 & 53 & 49 & 53 & 2130 & 2350 \\
\hline 36 & esc & 82 & 73 & 51 & 46 & 2200 & 2280 \\
\hline 37 & esc & 85 & 71 & 108 & 57 & 2590 & 2630 \\
\hline 38 & esc & 71 & 56 & 45 & 44 & 2260 & 2050 \\
\hline 39 & esc & 77 & 46 & 42 & 48 & 2000 & 1890 \\
\hline LSD $(P$ & $=0.01)$ & 9 & 32 & 28 & 21 & 480 & 540 \\
\hline
\end{tabular}

${ }^{z} \mathrm{pim}=$ Lycopersicon pimpinellifolium, per $=$ L. peruvianum, pen $=$ L. pennellii, hir $=L$. hirsutum, esc $=L$. esculentum.

acters should be useful for future studies of saline tolerance of mature tomato plants.

The FWL, DWL, DWS, and leaf $\mathrm{K}, \mathrm{N}-\mathrm{NO}_{3}$, and $\mathrm{Mg}$ concentration characters were not as affected by changes in salinity as plant height, FWS, and leaf concentrations of $\mathrm{Cl}$ and $\mathrm{Na}$. In $90 \%$ of cases, all six characters revealed significant differences and, therefore, would be useful for some salinity tolerance studies.

There were no significant differences between saline treatments for number of leaves, trusses, flowers, and fruits, stem thickness, and leaf $\mathrm{Ca}$ concentration (Table 1). Hence, these traits are not useful for measuring salinity tolerance of mature plants in experiments involving several species. However, they might be useful for comparative studies within a species.

In terms of the percentage of error variance in the analyses of variance, all the characters that showed little differences be- tween salt treatments (salt treatments significant for $<90 \%$ of the genotypes) also had percentage errors close to, or higher than, one-third of the total variance (Table 1). The only character presenting a high error and also significant differences between treatments in $>90 \%$ of the genotypes was leaf K concentration.

The third factor to be considered when assessing the suitability of a character for the evaluation of salinity tolerance is its uniformity of response to the saline treatments for most of the genotypes. When the mean values of treatments for each genotype were compared, the ranking of the four treatments was the same for leaf $\mathrm{Na}$ concentration and DWS in all 39 genotypes. For leaf $\mathrm{Cl}$ concentration, FWS, and DWL, it was the same in 38 genotypes. For plant height, the ranking was the same in 37 genotypes (Table 1). The character expressions for DWS, FWS, DWL, and plant height became less as salt concentration was increased, but the leaf concentrations of $\mathrm{Na}$ and $\mathrm{Cl}$ increased with salt concentration.

The saline treatments were found to be ranked similarly for number of trusses, flowers, and fruits, and for leaf Ca concentration in L. pimpinellifolium (Table 1). Treatment rankings were the same for stem thickness in $L$. pimpinellifolium, L. peruvianum, and L. hirsutum, and for FWL in L. pimpinellifolium, L. peruvianum, and L. pennellii. Rankings were the same for leaf $\mathrm{K}$ concentration in L. hirsutum, L. pimpinellifolium, and L. esculentum. However, because of their large error variance percentages, all these characters are unacceptable as predictors of tolerance.

Other characters, because they are different for each species, are not generally applicable, but they still have validity in certain cases. For example, number of leaves could be used because it is a character that changes with salt concentrations in $L$. hirsutum. Similarly, leaf $\mathrm{N}-\mathrm{NO}_{3}$ concentration in both $L$. pimpinellifolium and L. esculentum could be used. Leaf $\mathrm{Mg}$ concentration could be used to evaluate $L$. pimpinellifolium, $L$. hirsutum, and L. esculentum tolerance. The above three characters revealed significant differences between treatments for most of the genotypes, the mean values of their responses to saline treatments were ranked similarly, and their variance errors were low (Table 1).

Analysis of the data of the six characters that exhibited significant changes in all 39 genotypes showed that NaCl-treated plants of L. esculentum accessions had the fewest decreases compared with the controls for the four vegetative characters of plant height, DWL, FWS, and DWS. Entries of L. esculentum also had the most $\mathrm{Cl}$ and $\mathrm{Na}$ in the leaves (Table 2). In each species, except $L$. peruvianum, leaf $\mathrm{Cl}$ concentrations were similar or slightly higher than leaf $\mathrm{Na}$ concentrations (Table 2; LSD 0.01). In L. peruvianum, the levels of $\mathrm{Cl}$ in the leaf were more than double those of $\mathrm{Na}$. Five genotypes $(1,28,29,31$, and 37) revealed smaller decreases of their vegetative characters when compared with control plants than the other 34. All five showed high leaf concentrations of both $\mathrm{Cl}$ and $\mathrm{Na}$. Generally, those genotypes with smaller decreases of their vegetative characters than control plants had higher leaf concentrations of $\mathrm{Cl}$ and $\mathrm{Na}$. However, some genotypes belonging to wild species $(3,6$, and 26) showed small decreases of their vegetative characters and medium to low leaf concentrations of $\mathrm{Cl}$ and $\mathrm{Na}$.

\section{Discussion}

Changes in leaf concentrations of $\mathrm{Na}$ caused by changes in $\mathrm{NaCl}$ concentrations of the nutrient solution have been reported for L. esculentum, L. cheesmanii Riley, L. peruvianum, L. pen- 
nellii, and Solarium lycopersicoides Dun. (Phills et al., 1979; Sacher et al., 1983; Shannon et al., 1987). Our results are similar and they include two more species, L. pimpinellifolium and $L$. hirsutum. There appears to be no direct relationship between leaf $\mathrm{Cl}$ concentration and plant dry weight (Sacher et al., 1983). Our results are similar to those of Phills et al. (1979) because leaf $\mathrm{Cl}$ levels changed significantly in response to changes in the $\mathrm{NaCl}$ concentrations for all the species tested. The leaf concentration of $\mathrm{Mg}$ changes with $\mathrm{NaCl}$ concentration of the nutrient solution in several species, namely L. esculentum (Phills et al., 1979), L. pimpinellifolium, and L. hirsutum, but not in L, peruvianum and L. pennellii (Phills et al., 1979).

In the present work, plants usually were shorter at the higher salt concentrations, but some authors say that plant growth may increase slightly following treatment with low concentrations of $\mathrm{NaCl}$ (Nukaya et al,, 1979; Shannon et al., 1987).

The smaller number of leaves and flowers observed when growing plants on saline substrate is a typical stress response to temperature, humidity, or salinity (Wrona, 1983). The results of our study show that only in $62 \%$ of the cases (in which errors were greater than one-third of total variance) did the number of flowers and trusses decrease with an increase in $\mathrm{NaCl}$ concentration. This result suggests that both number of leaves and number of flowers were affected by factors independent of $\mathrm{NaCl}$ treatments.

Accessions of L. pimpinellifolium, L. pennellii, and L. esculentum are self-fertilizing, but, unexpectedly, showed no significant differences between number of fruits at low salt concentrations $\left(0.28\right.$ and $\left.0: 63 \mathrm{~S} \cdot \mathrm{m}^{-1}\right)$. At higher salt concentrations (1.39 and 2.1.5 S.m $\mathrm{m}^{-1}$ ), the number of fruits were significantly reduced. Small changes in number of fruits at low salt concentrations are reported (Rush and Epstein, 1981; ShaIhevet and Yaron, 1973).

Stem thickness, a measurement of plant vigor, showed little change with $\mathrm{NaCl}$ concentration in our study. Hall (1983) also reported that tomato stem thickness is not affected by salinity.

The three growth characters FWS, DWL, and DWS were good indicators of salinity tolerance. Hassan and Desouki (1982), Shannon (1979), and Shannon et al. (1987) used dry weight of the whole treated plants, expressed as a percentage of the dry weight of the whole control plants, as an index of salinity tolerance for L. esculentum, L. pennellii, and several hybrids of these species. Our results showed that the measurements of FWL and DWL gave higher error variances than FWS and DWS, possibly because some leaves may have abscised during plant development; consequently, the shoot and leaf weight characters should be interpreted with caution when evaluating adult plants.

\section{Literature Cited}

Dehan, K. and M. Tal. 1978. Salt tolerance in the wild relatives of the cultivated tomato: Responses of Solarium pennellii to high salinity. Irr. Sci. 1:71-76.

Epstein, E. 1983. Crops tolerant of salinity and other mineral stresses, p. 31-61. In: Ciba Foundation Symposium 97 (cd.). Better crops for food. Pitman Books, London.

Guerrier, G. 1984. Selectivity de fixation du sodium au niveau des embryons et des jeunes plantes sensible ou tolerante au NaCl. Can. J. Bet. 62:1791-1792.

Hall, D.A. 1983. The influence of nitrogen concentration and salinity of recirculating solutions on the early-season vigour and productivity of glasshouse tomatoes. J. Hort. Sci. 58:411-415.

Hassan, A.A. and J.A.M. Desouki. 1982. Tomato evaluation and selection for sodium chloride tolerance. Egypt. J. Hort. 9:153-162.

Johnson, C. M., R.P. Huston, and P.G. Ozanne. 1958. Measurement of microgram amounts of chlorine in plant materials. Agr. Food Chem. 6:114-118.

Norlyn, J.D. and E. Epstein. 1984. Variability in salt tolerance of four triticale lines at germination and emergence. Crop Sci. 24:10901092.

Nukaya, A.,. M. Masui, and A. Ishida. 1979. Salt tolerance of tomatoes. J. Jpn. Sot. Hort. Sci. 48:73-81. . . .

Phills, B. R., N.H. Peck, G.E, MacDonald, and R.W. Robinson. 1979. Differential response of Lycopersicon and Solanum species to salinity. J. Amer. Soc. Hort. Sci. 104:349-352.

Rush, D.W. and E. Epstein. 1981. Breeding and selection for salt tolerance by the incorporation of wild germplasm into a domestic tomato. J. Amer. Soc. Hort. Sci. 106:699-704.

Sacher, R. F., R.C. Staples, and R.W. Robinson. 1982. Saline tolerance in hybrids of Lycopersicon esculentum $x$ Solarium pennellii and selected breeding lines, p. 325-336. In: A. San Pietro (cd.). Biosaline research: A look to the future. Plenum Press, New York.

Sacher, R. F., R.C. Staples, and R.W. Robinson. 1983. Ion regulation and response of tomato to sodium chloride: A homeostatic system. J. Amer. Soc. Hort. Sci. 108:566-569.

Shalhevet, J. and B. Yaron. 1973. Effect of soil and water salinity on tomato growth. Plant \& Soil 39:285-292.

Shannon, M.C. 1979. In quest of rapid screening techniques for plant salt tolerance. HortScience 14:587-589.

Shannon, M.C. 1984. Breeding, selection and the genetics of salt tolerance, p. 231-254. In: R.C. Staples and G.H. Toenniessen (eds.). Salinity tolerance in plants. Wiley, New York.

Shannon, M. C., J.W. Gronwald, and M. Tal. 1987. Effects of salinity on growth and accumulation of organic and inorganic ions in cultivated and wild tomato species. J. Amer. Soc. Hort. Sci. 112:416423.

Storey, R. and R.G. Wyn Jones. 1977. Quaternary ammonium compounds in plants in relation to salt resistance. Photochemistry 16:447453.

Tal, M. 1971. Salt tolerance in the wild relatives of the cultivated tomato: Responses of Lycopersicon esculentum, L. peruvianum and L. esculentum minor to sodium chloride solution. Austral. J. Agr. Res. 22:631-638.

Tal, M. and M.C. Shannon. 1983. Salt tolerance in the wild relatives of the cultivated tomato: Responses of Lycopersicon esculentum, $L$. cheesmanii, L. peruvianum, Solarium pennellii and $\mathrm{F}_{1}$ hybrids to high salinity. Austr. J. Plant Physiol. 10:109-117.

West, D. W., I.F. Merrigan, J.A. Taylor, and G.M. Collins. 1979. Soil salinity gradients and growth of tomato plants under drip irrigation. Soil Sci. 127:281-291.

Wrona, A.F. 1983. Salt relations of genotypes of the tomato, Lycopersicon spp. PhD Diss., Univ. of California, Davis. (Diss. Abstr. 84-07938). 